\title{
Study of the Equivalent Load on the Local Component of the Car Body Ye SONG ${ }^{1, a,{ }^{*}}$, Ping-Bo WU ${ }^{1, b}$, Lu JIA ${ }^{1, c}$ \\ ${ }^{1}$ State Key Laboratory of Traction Power, Southwest Jiaotong University, Chengdu 610031, China

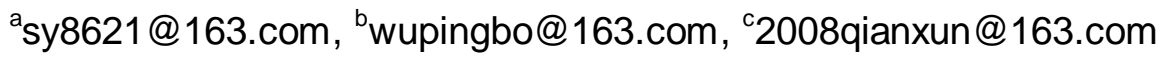 \\ ${ }^{*}$ Corresponding author
}

Keywords: High-speed Carbody, Parts, Underframe Static Strength, Equivalent Load.

\begin{abstract}
The purpose of this research is to put forward a fatigue strength test method for the key parts of the carbody. The body is an important load-bearing part of railway vehicle. The underframe is the basis of carbody structure, is the most main body bearing part. This paper put a more in-depth discussed about how to accurately determine a reasonable constraints and equivalent load when the local component in the test. It could determine more realistic response the carbody underframe's boundary conditions through contrasting concern regional's trends in stress and deformation by finite element analysis of vehicle model and the underframe locally model. Based on the minimal total error theory of stress on the region of interest to obtaining for the equivalent load of the vehicle underframe components in the test through contrasting the stresses in the region of interest in the vehicle model and the underframe locally model.
\end{abstract}

\section{Introduction}

The carbody is the main component of high-speed trains, which has received a variety combined action of alternating loads. In order to improve the safety of high-speed trains, to carry out research body fatigue strength, it is very important. National scholars conducted extensive studies on the car body. There are: Numerical and experimental studies carried out by Korea's Jung-Seok Kim were aimed to assess the natural frequency of the Korea composite material of tilting train car body $[1,2,6]$. And experimental studies were carried out on the car body stiffness and static strength. The crack on the EMU car body chassis was evaluated by Hyun-Kyu Jun [3]; the body simulation and the experiment on the boundary constrains were studied by T.H. Lee $[4,5]$; the coupling vibration between the subway car body and the bogie was analyzed by Gong Dao [7]. The static and dynamic stress numerical analysis of railway wagons and passenger cars were researched by Baykasoglu [8].

Due to the huge body size, based on the current test conditions the main vehicle test platform at home and abroad, it is difficult for the whole body fatigue test, only a few countries have carried out experimental research body fatigue. Japanese Ishizuka Hiromichi did thorough experiments and theoretical studies on the car body fatigue $[9,10]$. Strength evaluation method is proposed for the car body fatigue phenomena, using S-N curve of the car body material to evaluate fatigue strength; Sung-II Seo and so on from Korean Railway Research Institute studied the necessity to evaluate the fatigue strength of aluminum alloy car body for urban transport vehicles with the large scale test method simulating the actual dynamic loads [12], and the fatigue failures of the car body are investigated. In this context, it is hoped by the local important bearing structure of the body fatigue tests to verify the fatigue life of the car body. Therefore, for local car body especially the hold pillow slow of the underframe bearing the most complex loading, studying on fatigue test appears very important. To do a partial body fatigue strength test, conforming its boundary conditions and equivalent load becomes the core of the study.

\section{Introduction of the Car Body and the Underframe}

In this research, with a certain type of the car body of high-speed emu as the research object, the type of the emu maximum operating speed is $350 \mathrm{~km} / \mathrm{h}$. Modular design to achieve a higher standardization and serialization. Well vehicle sealing can make the passengers avoid the wave influence produced by the 
train through the tunnel and two trains meeting in the tunnel. The body mainly consists of the underframe, side walls, roof, end wall, and car body accessories, etc. The car body structure is shown in figure 1.

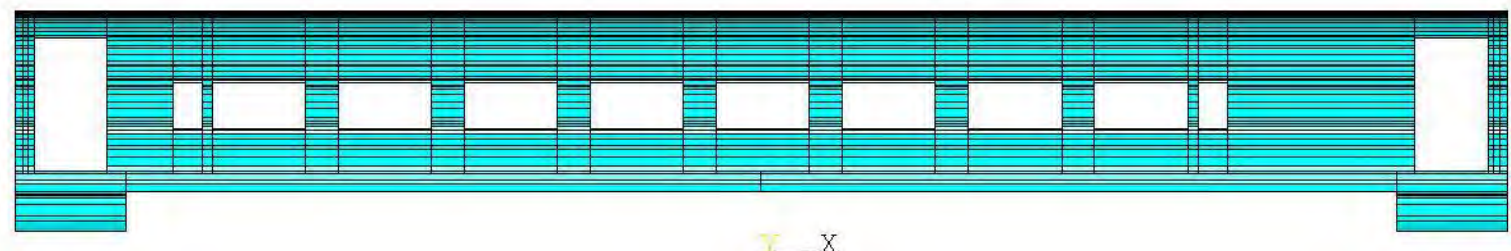

Fig. 1 Car Body Structure Geometry Model

Vehicle underframe consists of traction beam, side beams (beam), end beam and corrugated floor, etc. Traction beam is mainly welded by aluminum alloy extrusion profiles and aluminum alloy plates together, setting additional structure for coupling buffer device. Side beam is located in the underframe under floor between left and right sides of the longitudinal beam, is the key component connecting underframe and side wall into a cylinder. Underframe corrugated flooring is made through a long extruded aluminum structure. In order to enhance the longitudinal strength, the reinforcement structure is set in the longitudinal direction. The FE model is set up in the software ANSYS, as shown in figure 2.

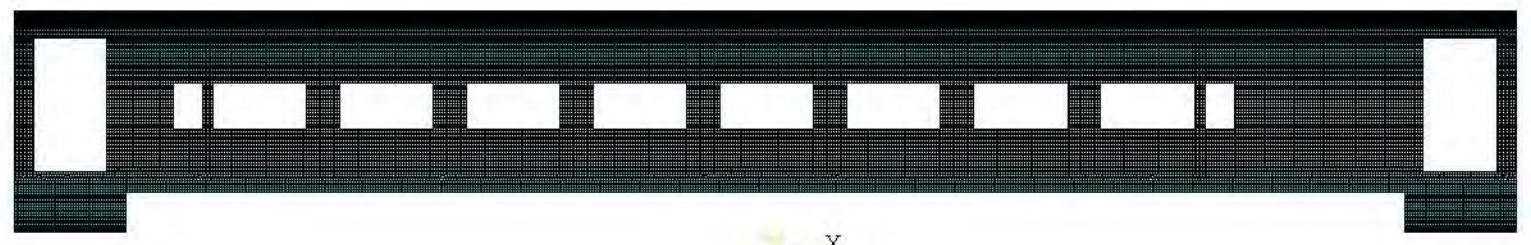

Fig. 2 Car Body Finite Element Model

\section{The Exploration of the Equivalent Load Method}

\section{The Exploration of the Equivalent Load Method}

Load of the existing standards are aimed at the car body load under the condition of the entire body. The car body underframe local component load is different from the entire car body load. So the standard vehicle load cannot be applied directly to local component fatigue strength test of car body underframe. In addition, the local component itself is cut from the entire car body. That is to say, cutting edge of local components has a strong uncertainty. However, car body and its components are in the experimental stage. A reasonable load condition of the specimen and constraint boundary condition are the key factor, decided to test can be completed smoothly.

In general, in the local component of car body underframe fatigue strength test there are two key problems to be solved:

Starting from the actual condition of experiment, how to determine the boundary conditions of local components of the body underframe, and the effectiveness of the proposed solution can be reasonable evaluated.

Local components at the underframe of the car body, on the basis of reasonable boundary conditions of constraint solution, how to get the car body underframe local component reasonable load conditions, can make it equivalent with the vehicle load under the condition of the entire car body.

In the actual project, often encounter only need to care for the analysis of local area. But if the grid is too sparse, it won't get satisfied results and even produce stress singularity, and the part to focus on areas outside, the grid density is enough. At this point you can use the sub-model analysis technology to solve.

The sub-model method analysis process generally includes five steps. First, set up and analyze the rough model, and ignore the small features, and divide the coarser mesh. Secondly, establish the sub-model, complementary small structural features ignored in front, and further mesh refinement. Again, give the sub-model the specified analysis type, the calculated results of the rough model generated cutting boundary interpolation as sub-model boundary conditions. Then, other original loads are applied on the sub-model and boundary conditions and complete the sub-model analysis. Finally, verify the cutting 
boundary and the distance in stress concentration regions to ensure accuracy. Sub-model analysis only works for body and shell elements, usually a whole model to sub model with shell to shell, body to body, shell to the body.

Through the study found that: the sub-model method and research of sub-structure fatigue strength test have a lot of in common, are based on integral model to the local model as the research process. Both requirements are put forward for local model boundary conditions. Compare the calculation results of local model and whole model, to carry out inspection. Therefore, adopt the similar method of substructure for studying the local structure fatigue strength test.

\section{The Idea and Method of Equivalent Calculation of the Underframe Model}

After the calculation comparison of the hold pillow slow local model and the entire car body, in combined with the requirement of experiment, starting from the basic conditions of test, summarize the basic idea of equivalent calculation analysis of local model of the car body underframe.

1) Make the refinement processing to the grid of the hold pillow slow partial in the whole car body, shown in figure 3. Make sure that the grid density is consistent with the hold pillow slow local model. After so as to ensure the accuracy of calculation, make it convenient contrast the two calculation results of the two models.

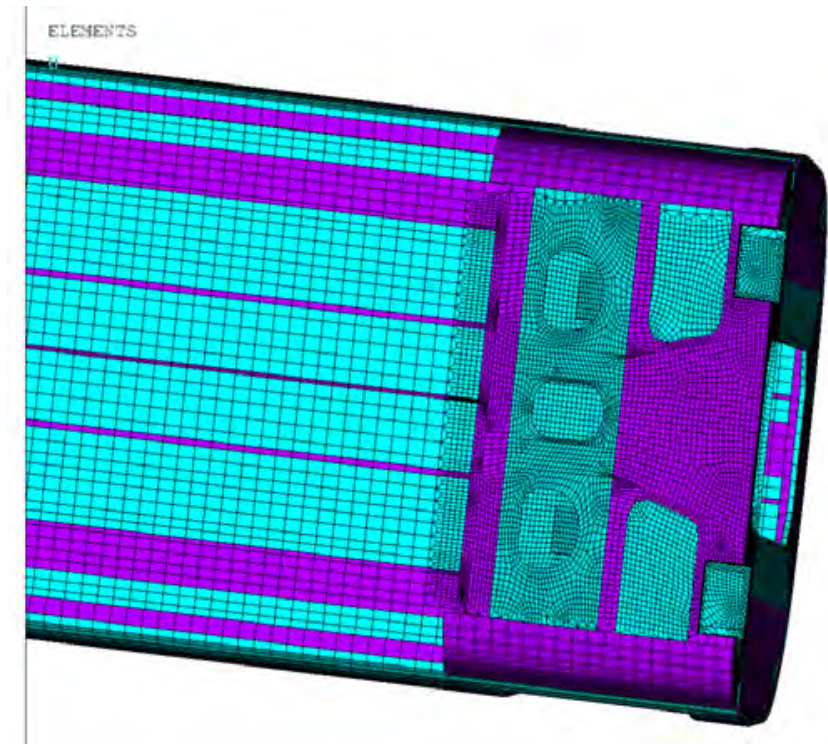

Fig. 3 Grid Refinement in the Partial in the Entire Vehicle Model

2) In the standard "EN12663-2010" regulation of load conditions, Using the finite element method, analyze stress state and distribution of the hold pillow slow partial in the CRH3 high-speed train vehicle model.

3)The above calculation results and the corresponding calculation results in the cases of the entire vehicle model were compared. Under the condition of without considering adding auxiliary structures, transform local constraint boundary conditions of the model. And analyze each constraint boundary conditions on the influence of the local model calculation results, looking for reasonable boundary constraints.

4)If not adding auxiliary structure is unable to get reasonable constraint boundary conditions. It is needed to accord to the local geometric structure analysis model of the vehicle where constraint boundary conditions of the area is most likely not appropriate. Try to modify the local model. According to the local model in the position of the vehicle model, under the condition of no affection the stress state of structure, simulate the vehicle structure, adding auxiliary structures on the experiment sample to set up the new model. Transform the constraints of boundary conditions in the new local model, and analyze its impact on local model calculation results, then contrast the calculation results of the entire model.

5)After repeated comparison and analysis with vehicle model calculation results, Found in the local model, stress state and distribution of basic calculation result with the entire vehicle model can roughly consistent. But now the constrained boundary condition is not necessarily correct, need further 
verification.

6)Under the premise of model calculation result is not affected, we need to try to streamline of secondary structure, in order to meet the test requirements, to determine the ultimate constraint boundary conditions.

7)Under the constraints of the boundary conditions were determined; the finite element analysis was carried out on the local model of car body. From key parts stress equivalent, after a reasonable calculation, with the full car body calculation results for reference, obtain the local model of equivalent load condition.

Equivalent calculation and analysis process of local model be showed in figure 4 .

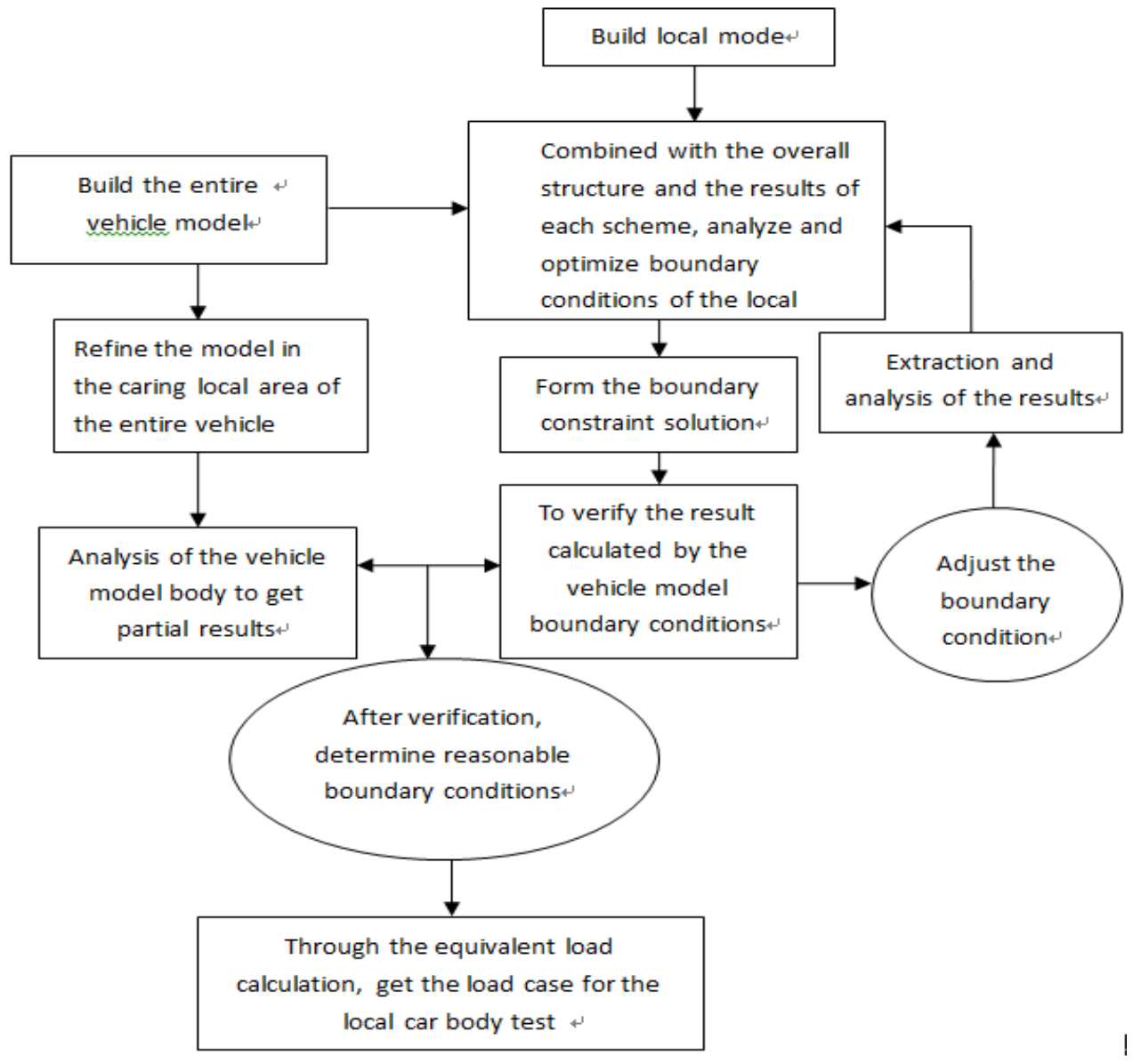

Fig. 4 Equivalent Calculation and Analysis Process of Local Model

\section{The Finite Element Strength Analysis}

\section{Car Body Static Strength Case}

The largest vertical force

According to the provisions in the EN132661-2010 to get maximum static vertical force as follows[11]:

$$
F_{z E}=1.3 g\left(m_{1} / 25+m_{2}\right)=36.2 \mathrm{kN}
$$

The largest longitudinal force

EN12663-2010 prescribed body parts in the buffer coupler withstand tensile and compressive longitudinal load below:

The maximum compression load $F_{x E}=1500 \mathrm{kN}$;

The maximum tensile load $F_{x E}=-1000 \mathrm{kN}$;

According to the EN12663-2010, make some harsh calculation cases of high speed emu car body static strength, as shown in table 1. 
Tab. 1 Car Body Static Strength Load Cases

\begin{tabular}{ccc}
\hline Case number & Vertical load $(\mathrm{kN})$ & $\begin{array}{c}\text { Longitudinal equivalent } \\
\text { load }(\mathrm{kN})\end{array}$ \\
\hline 1 & 0 & $1500 \mathrm{kN}$ \\
2 & 0 & $-1000 \mathrm{kN}$ \\
3 & 36 & $1500 \mathrm{kN}$ \\
4 & 36 & $-1000 \mathrm{kN}$ \\
\hline
\end{tabular}

\section{Car Body Strength Evaluation Standard and Material Properties}

Under the condition of the cases listed in table 1, the maximum stress of each node in car body does not exceed the yield stress of material, is the necessary condition to ensure the basic function of the car body. High-speed train body material is aluminum alloy.

The material properties of the local component on the car body underframe in the following table 2 .

Tab. 2 Material Properties

\begin{tabular}{ccccc}
\hline Type & $\begin{array}{c}\text { name of the } \\
\text { material }\end{array}$ & $\begin{array}{c}\text { elasticity } \\
\text { modulus [Gpa] }\end{array}$ & $\begin{array}{c}\text { Minimum yield } \\
\text { strength[Mpa] }\end{array}$ & $\begin{array}{c}\text { Minimum tensile } \\
\text { limit[Mpa] }\end{array}$ \\
\hline aluminum alloy & 6005A-T6 & 0.7 & 270 & 290 \\
\hline
\end{tabular}

\section{Local Partial Strength Analyses under the Entire Car Body}

The finite element calculation is carried out for the entire car body model in accordance with the cases listed in table 1. Local finite element analysis results of the hold pillow slow is extracted as follows:

Case 1: Superior longitudinal compressive force $1500 \mathrm{kN}$.

Under the load condition of case 1, the maximum Von mises equivalent stress in hold pillow slow is $207 \mathrm{Mpa}$, the material allowable stress is $215 \mathrm{Mpa}$ The stress value is in the range of allowable stress value. The largest equivalent stress unit is located in the middle of backplane backend. The von mises stress nephogram and deformation nephogram are shown in figure 5.

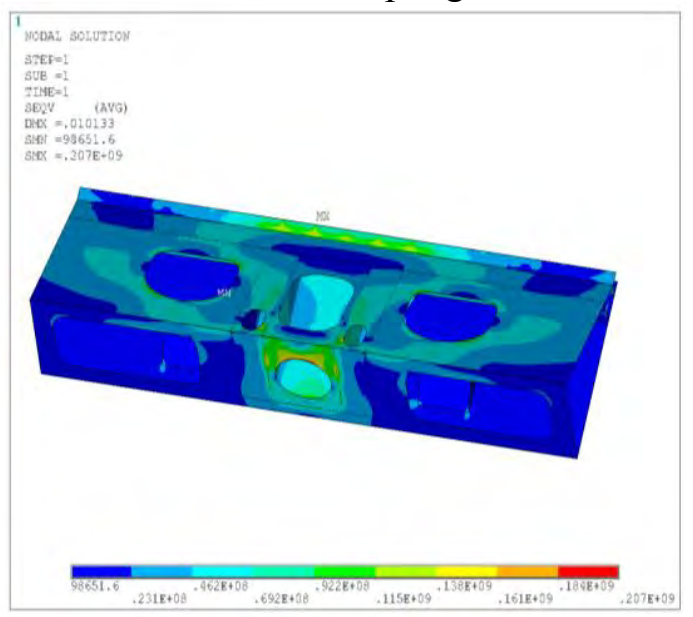

(a)The whole nephogram

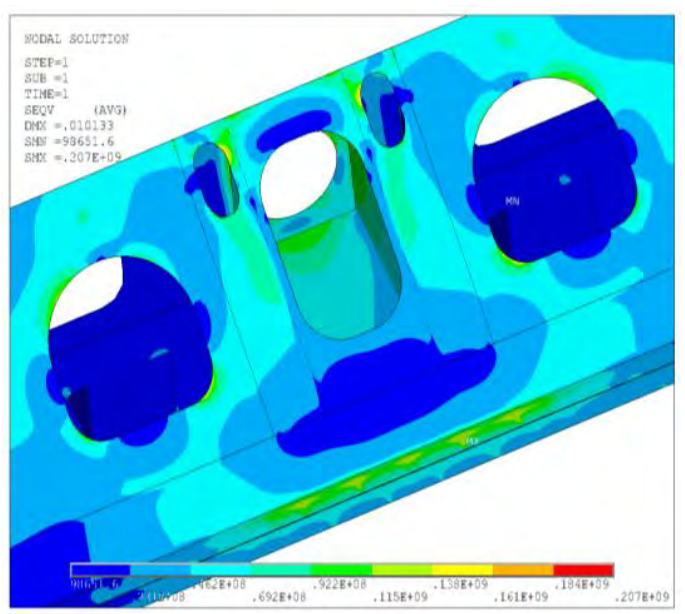

(b)The local nephogram

Fig . 5 Von Mises Stress Nephogram of the Local Car Body in Case 1

Case 2: Superior longitudinal tensile force $-1000 \mathrm{kN}$

Under the load condition of case 2, the maximum Von mises equivalent stress in hold pillow slow is $125 \mathrm{Mpa}$, the material allowable stress is $215 \mathrm{Mpa}$. The stress value is in the range of allowable stress value. The largest equivalent stress unit is located in the middle of backplane backend. The von mises stress nephogram and deformation nephogram are shown in figure 6. 


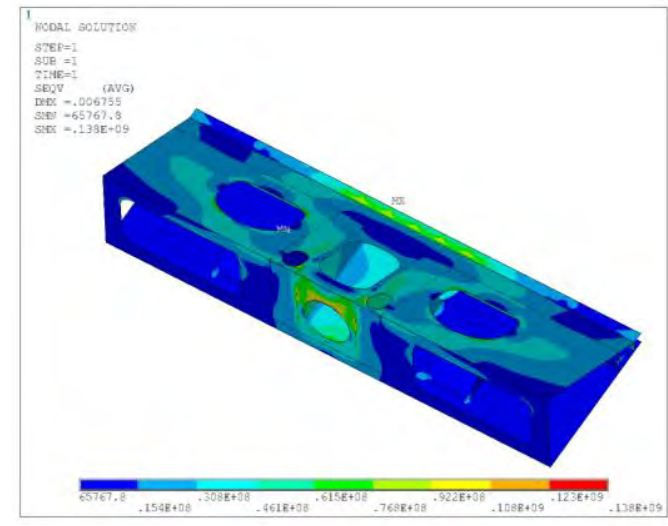

(1)The whole nephogram

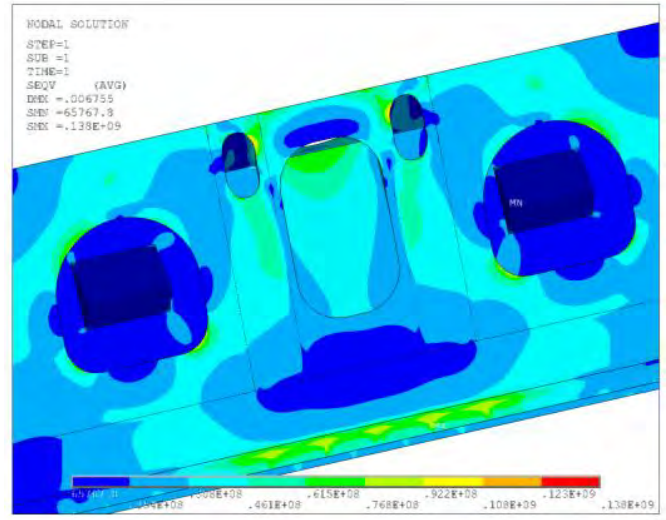

(2)The local nephogram

Fig. 6 Von Mises Stress Nephogram of the Local Car Body in Case 2

Case 3: Superior longitudinal compressive force $1500 \mathrm{kN}+$ static vertical force $36 \mathrm{kN}$

Under the load condition of case 3, the maximum Von mises equivalent stress in the hold pillow slow is $204 \mathrm{Mpa}$, the material allowable stress is $215 \mathrm{Mpa}$. The stress value is in the range of allowable stress value. The largest equivalent stress unit is located in the middle of backplane backend. The von Mises stress nephogram and deformation nephogram are shown in figure 7.

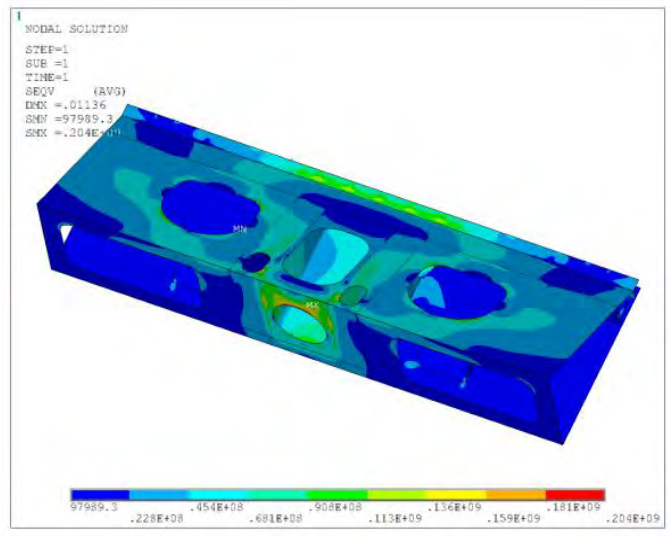

(a)The whole nephogram

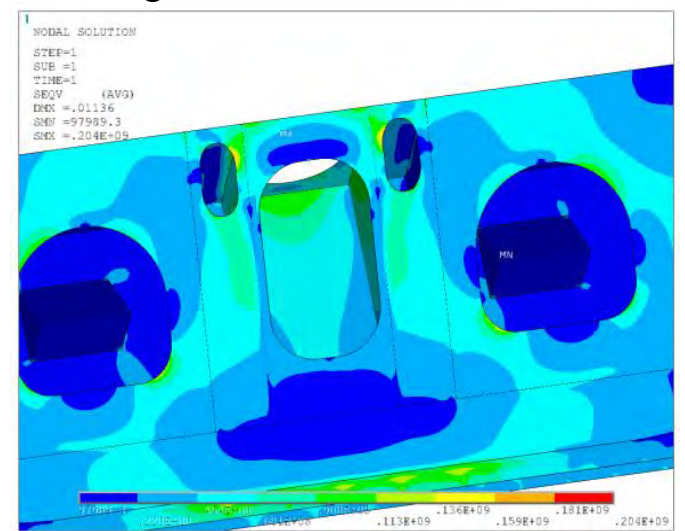

(b)The local nephogram

Fig. 7 Von Mises Stress Nephogram of the Local Car Body in Case 3

Case 4: Superior longitudinal tensile force $-1000 \mathrm{kN}+$ static vertical force $36 \mathrm{kN}$

Under the load condition of case 4, the maximum Von mises equivalent stress in the hold pillow slow is $155 \mathrm{Mpa}$, the material allowable stress is $215 \mathrm{Mpa}$. .The stress value is in the range of allowable stress value. The largest equivalent stress unit is located in coupling longitudinal load loading area. The von mises stress nephogram and deformation nephogram are shown in figure 8.

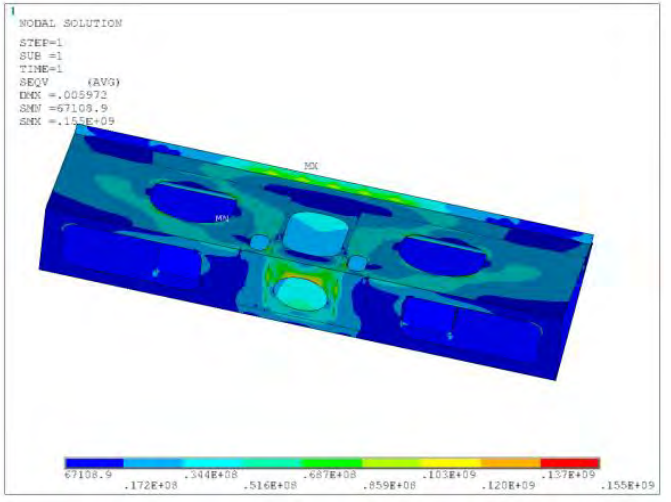

(a)The whole nephogram

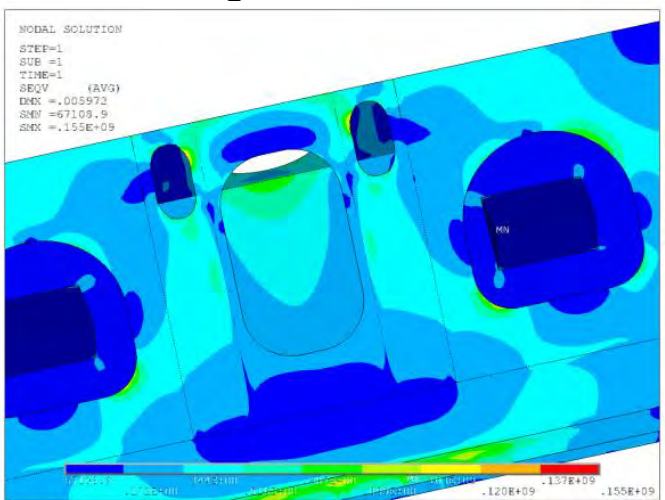

(b)The local nephogram

Fig. 8 Von Mises Stress Nephogram of the Local Car Body in Case 4 


\section{The Strength of the Individual Local Part of the Car Body Analysis}

Vehicle underframe hold pillow slow as part of the body, its structural is welded by the outside three plates and the middle four risers. So when choosing displacement change trend contrast area, select the nodes along with every weld area as the observation area. Look from structural analysis, in this paper mainly selected the 12 main weld area. As shown in figure 9. According to section 3.2 of the car body underframe local model with equivalent calculation are presented, Detailed analysis and calculation of the constraint conditions and equivalent load for the underframe local model were carried out, and finally find a reasonable constraint conditions and equivalent load.

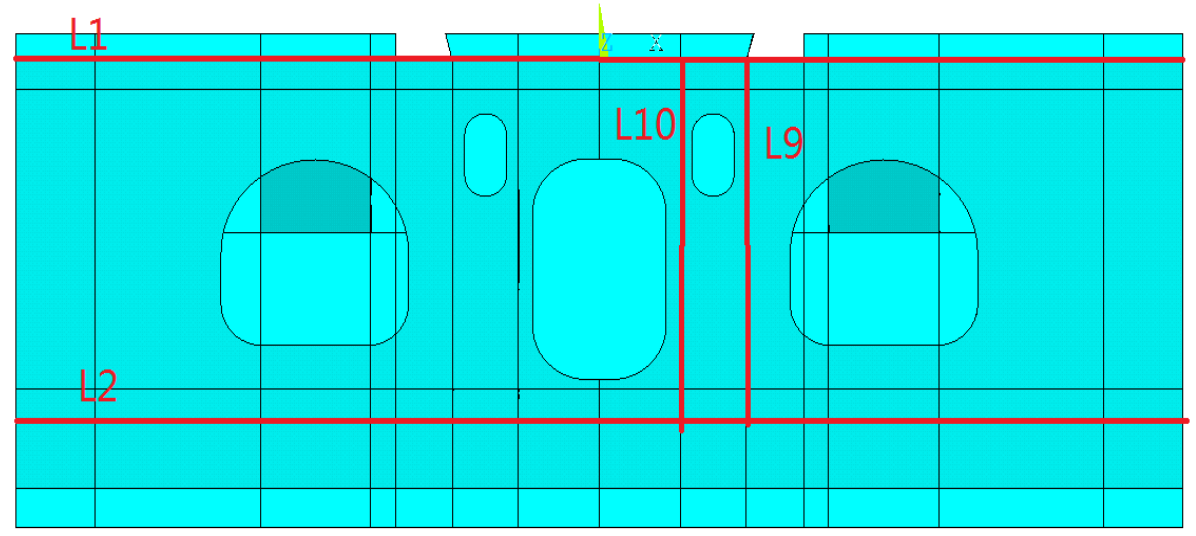

Fig. 9 Main Weld Location under the Floor

By studying the various constraints imposed in the longitudinal and vertical plan, Analyze the impact of longitudinal, vertical different constraint solution on the calculation results of car body underframe hold pillow slow. From the calculation results of various constraint solution, No matter from the whole distribution of Von mises stress nephogram, or the deformation trend of key areas, they all can't correspond to the calculated results of the entire vehicle model. Hence, it is necessary to add auxiliary structure in the region of the longitudinal load plate.

After the analysis the result of the whole vehicle model calculation, near the original model loading board, the main structure in the entire vehicle structure are added. As shown in figure 10.

$U \mathrm{x}=0, \mathrm{Uz}=0$

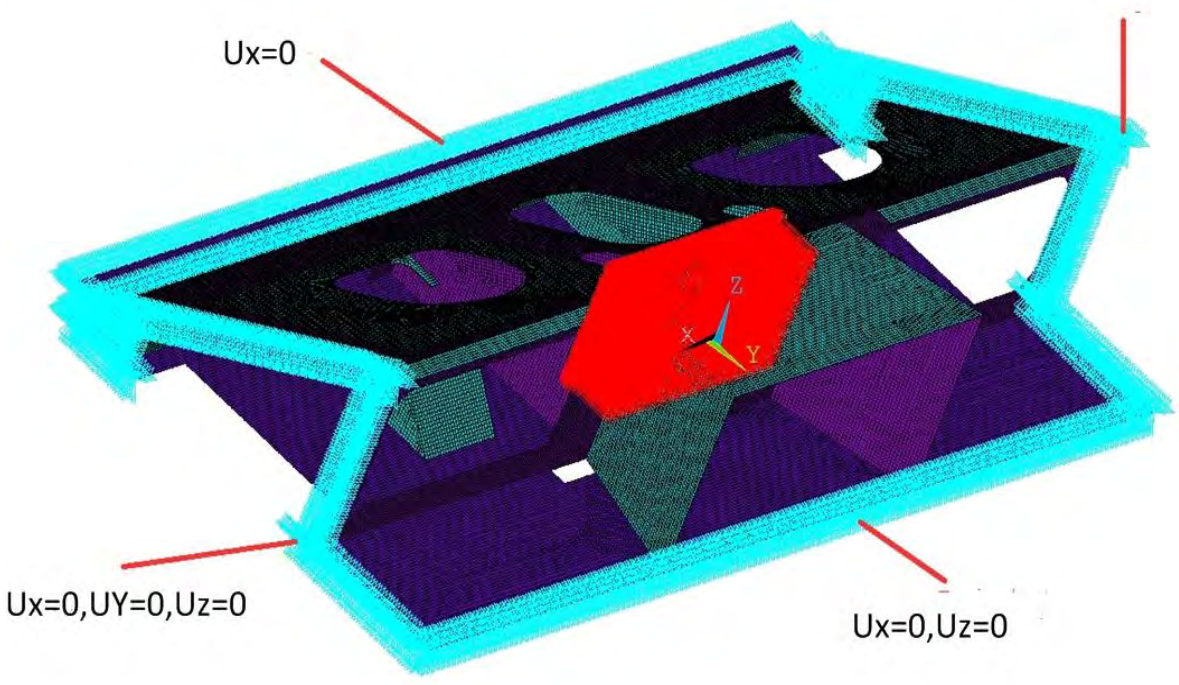

Fig. 10 The Condition of Reasonable Boundary Conditions

Under the condition of reasonable boundary conditions, longitudinal and vertical load are loaded on the local hold pillow slow of the underframe to verify the reasonable scheme. Calculation of the stress distribution nephogram and key weld area mainly displacement trend diagram as shown below: 
Stress distribution nephogram

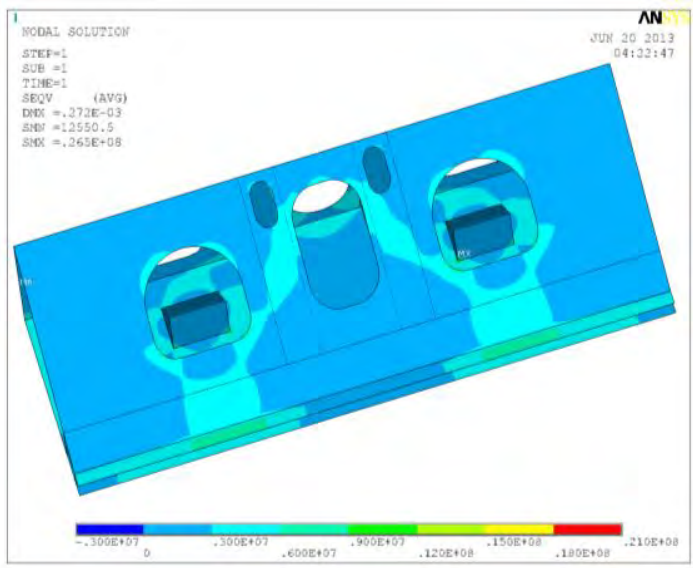

(a)The entire car body model

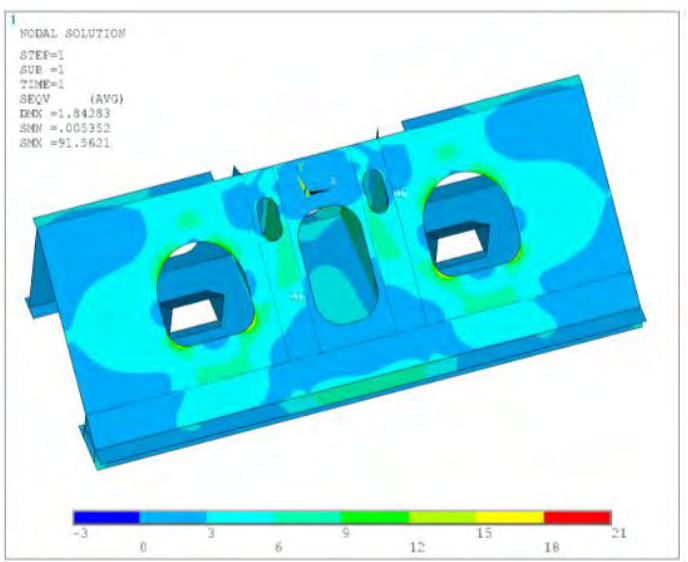

(b)Hold pillow slow local model

Fig. 11 the Contrast of the Von Misses Stress Distribution Nephogram on the Bottom Plate

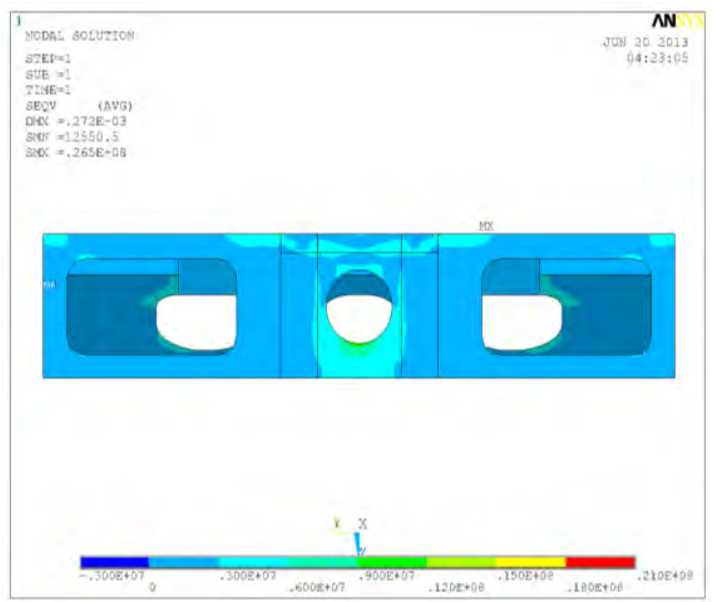

(a)The entire car body model

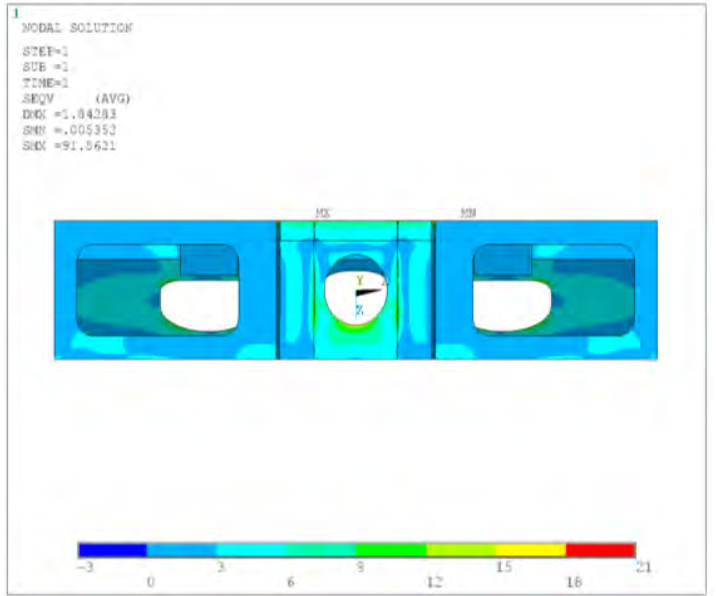

(b)Hold pillow slow local model

Fig. 12 the Contrast of the Von Misses Stress Distribution Nephogram on the Vertical Loading

Contrast of key weld area mainly displacement change trend

Below 13 and 14 shows under the combination load condition of the longitudinal load and vertical load, comparing displacement trends on weld L1:

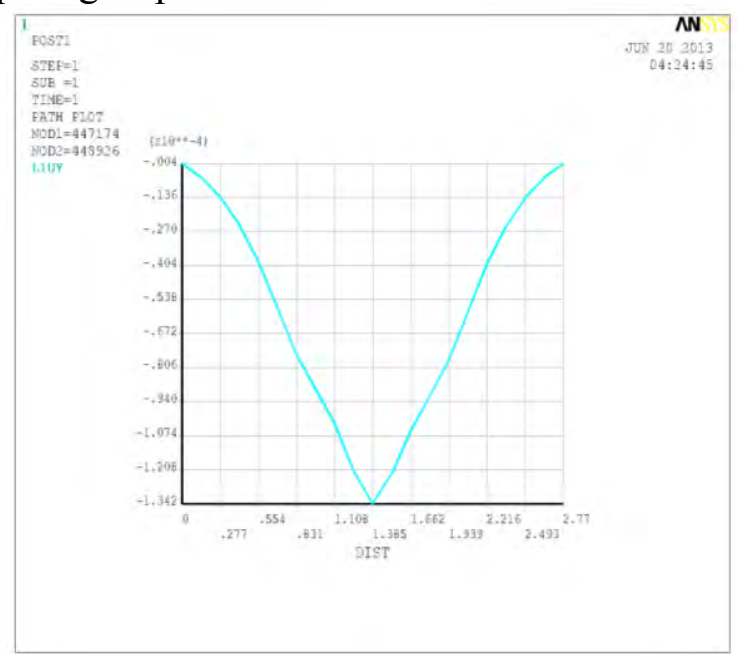

(a)The entire car body model

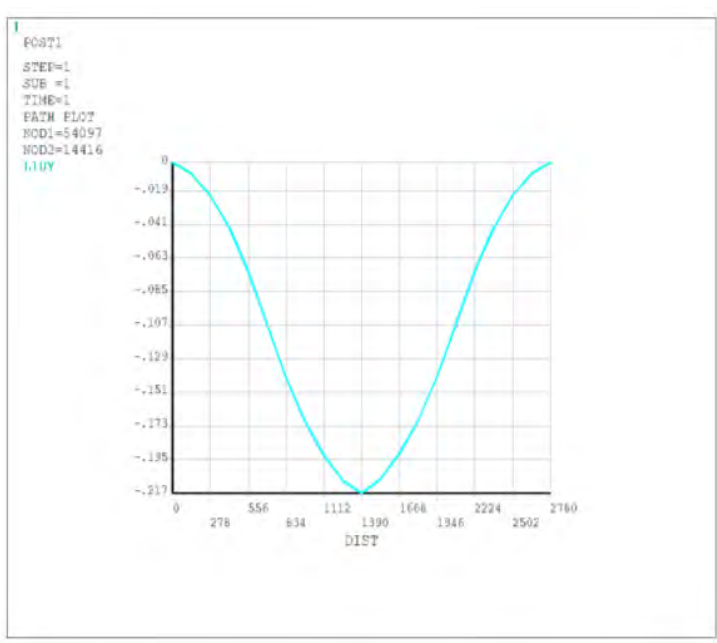

(b)Hold pillow slow local model

Fig. 13 the Longitudinal Displacement Change Trend of Weld L1 


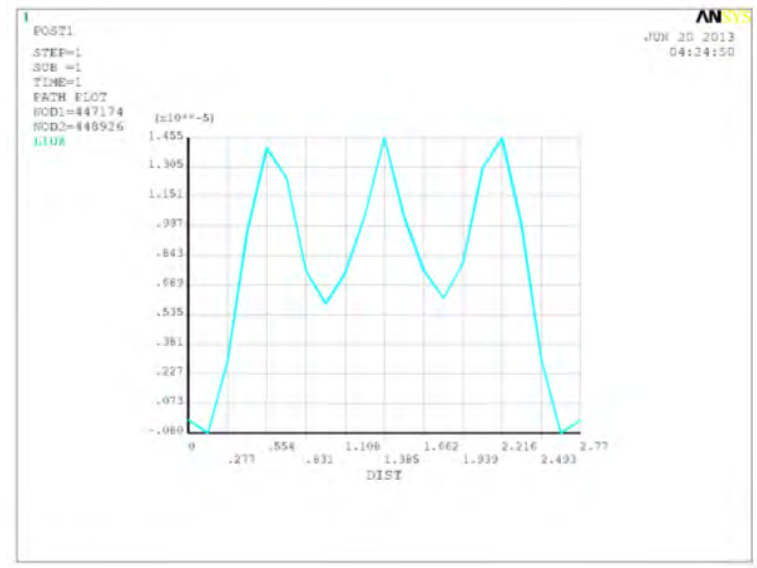

(a)The entire car body model

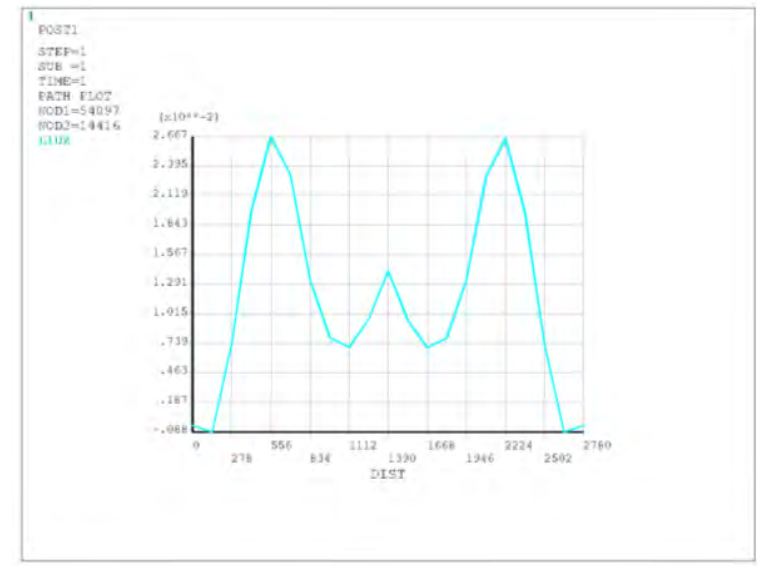

(b)The hold pillow slow local model

Fig. 14 the Vertical Displacement Change Trend of Weld L1

It can be seen from figure 13 that the stress distribution of the entire car body model and the hold pillow slow local model are the same. The distribution of the stress concentration area and the calculated results also match.

Through figure 14 it can be seen that the longitudinal and the vertical displacement change trend of the hold pillow slow is the same as the entire model.

\section{The Proposal of Equivalent Load of the Underframe Local Model}

Comparing the result calculated by 4.4 it can be seen clearly, although the regularity of the stress distribution on the concentration area of the local model is consistent with the entire car body model, the size of the stress is obviously different. This requires a local model load cases must be modified, in order to basically keep consistent with the stress size on the concentration area of the entire car body model.

If choose one stress concentration node or a small part of the stress concentration node as a comparison object, Or simply use stress ratio to determine the equivalent load, all the methods will make the results too one-sided. Should be as much as possible to make effective node calculations involved in the evaluation of the equivalent load conditions, introducing the concept of focus on measuring point total error rate. From the principle of key parts stress equivalent, select by comparing the key weld area, which are calculated as object. When focus on measuring point with minimum total error rate, the load is the equivalent load. It can be expressed as the following:

$$
\partial_{\min }=\min \left(\partial\left(F_{e q}, a_{i}, b_{i}\right)\right)
$$

Where $\partial$ is the total error rate of focus node stress; $a_{i}$ is the direction of the stress value of each comparison node in the entire carbody model; $b_{i}$ is the direction of the stress corresponding node of local test object; $F_{\text {eq }}$ is equivalent load.

The total error rate of focus node stress can be expressed as shown in the following formula:

$$
\begin{aligned}
& \partial=\sum_{i=1}^{n} m_{i} \Delta_{i} \\
& m_{i}=a_{i} / a_{\min } \\
& \Delta_{i}=\left|a_{i}-b_{i}\right| / a_{i}
\end{aligned}
$$

Where $m_{i}$ is corresponding impact factor of focus node stress. This parameter can be adjusted the contribution of the large stress node to the total error rate, reducing the contribution of the less important node to the total error rate. $\Delta_{i}$ is the relative error rate for each node in focus. 
Through this method to obtain the feasibility analysis of equivalent load conditions:

Equivalent longitudinal load: In the process of calculating the equivalent longitudinal load, In $5 \mathrm{kN}$ for a step, set the load steps. After calculation, When the entire car body model is in the longitudinal load of $88 \mathrm{kN}$, The equivalent error values $\partial$ regularly changes along with $F_{z}$. As shown in figure 15 . When the local hold pillow slow is in the longitudinal load of $45 \mathrm{kN}$, the equivalent error values $\partial$ is minimum. That is to say $F_{y}=45 \mathrm{kN}$ is the equivalent vertical load when $F_{y}=36 \mathrm{kN}$ in the entire car body.

The equivalent vertical load: In the process of calculating the equivalent vertical load, In $3 \mathrm{kN}$ for a step, set the load steps. After calculation, When the entire car body model is in the vertical load of $36 \mathrm{kN}$, The equivalent error values $\partial$ regularly changes along with $F_{z}$. As shown in figure A. When the local hold pillow slow is in the vertical load of $27 \mathrm{kN}$, the equivalent error values $\partial$ is minimum. That is to say $F_{z}=27 \mathrm{kN}$ is the equivalent vertical load when $F_{z}=36 \mathrm{kN}$ in the entire car body.

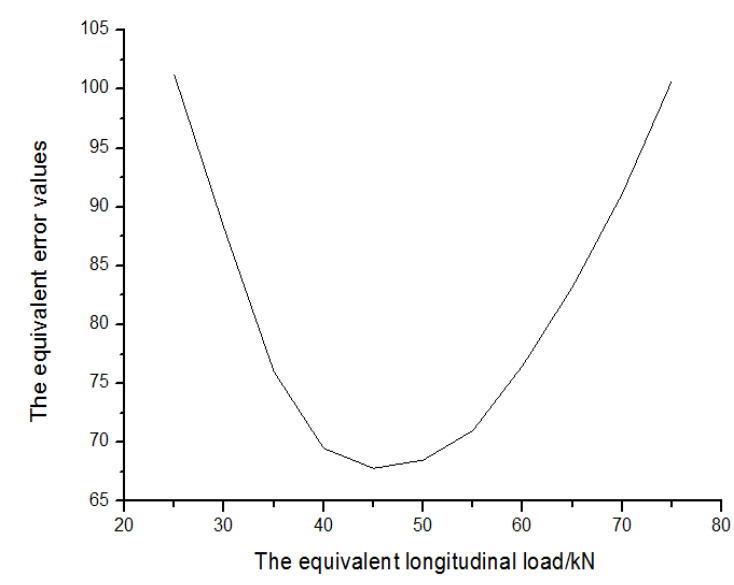

Fig. 15 the Corresponding Relationship Longitudinal Load and Error Values

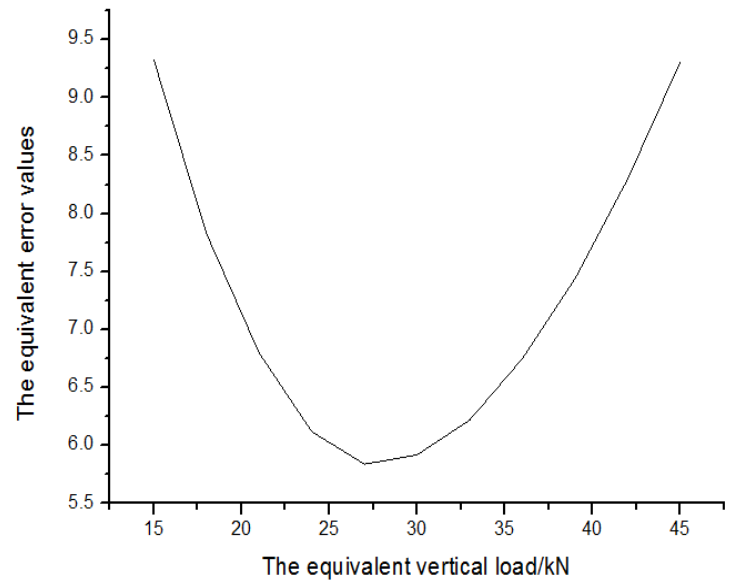

Fig. 16 the Corresponding Relationship Longitudinal Load and Error Values

\section{Conclusion and Prospect}

This research is focused on how to determine reasonable constraint conditions in the test for the car body underframe local part. Meanwhile, in the reasonable constrain condition, how to get the equivalent load in relative to the entire car body. Through the depth research, the following conclusions:

1. Based on the sub-model substructure analysis method, structure fatigue strength test method is gained.

2. Through the finite element calculation of the entire car body and the local model in the hold pillow slow of the underframe, according to the stress equivalent principle, Compare the distribution of stress concentration area and change trend of key position displacement. The reasonable constraint conditions required by the local fatigue strength test can be put forward.

3. Under the condition of reasonable constraint, Through compared with calculation results of car body vehicle model reasonable load conditions can be met the requirement test of car body underframe hold pillow slow local model, namely local corresponding equivalent load.

Through the experimental study for the railway vehicle body fatigue test provides the basis for the establishment of norms. For the subsequent development of new products, provides a good test platform, effectively saving the cost of developing and testing.

\section{Acknowledgement}

This research was financially supported National "863" plan project High-speed train spectrum module construction and key technology of integration design (2012AA112001-02). Rolling stock basic theory and standard research - the emu aluminum alloy car-body structure fatigue strength design theory and experimental study(2014J012-C). High-speed emu car body fatigue test technology research (2012TPL-T01). 


\section{References}

[1]Jung-Seok Kim and Jong-Cheol Jeong. Natural frequency evaluation of a composite train carbody with length of $23 \mathrm{~m}$. Composites Science and Technology 2006; 66: 2272-2283.

[2]Jung-Seok Kim, Sang-Jin Lee and Kwang-Bok Shin. Manufacturing and structural safety evaluation of a composite train carbody. Composite Structures 2007; 78: 468-476.

[3]Hyun-Kyu Jun, Hyun-Seung Jung and Dong-Hyung Lee. Fatigue crack evaluation on the underframe of EMU carbody. Procedia Engineering 2010; 2: 893-900.

[4]T.H. Lee and J.J. Jung. A sampling technique enhancing accuracy and efficiency of metamodel-based RBDO: Constraint boundary sampling. Computers and Structures 2008; 86: 1463-1476.

[5]Kwang Bok Shin and Seong Ho Hahn. Evaluation of the structural integrity of hybrid railway carriage structures including the ageing effects of composite materials. Composite Structures 2005; 68: 129-137.

[6]Jung-Seok Kim and Seong-Kyun Chung. A study on the low-velocity impact response of laminates for composite railway bodyshells. Composite Structures 2007; 77: 484-492.

[7]Dao Gong, Wenjing Sun and Jinsong Zhou. Analysis on the Vertical Coupled Vibration between Bogies and Metro Car Body. Procedia Engineering 2011; 16: 825-831.

[8]C. Baykasoglu, E. Sunbuloglu and S. E. Bozdag. Numerical static and dynamic stress analysis on railway passenger and freight car models. International Iron \& Steel Symposium, Karabük, Türkiye, 2012.

[9]Oomura, K., Okuno, S., Kawai, S., Masai, K. and Kasai, Y., Fatigue Test of an actual car body structure(1st report, the testing method and its accuracy), Trans. Jpn. Soc. Mech. Eng. 1992, 58(545): 20-25.

[10]Oomura, K., Okuno, S., Kawai, S., Masai, K. and Kasai, Y., Fatigue Test of an actual car body structure(2st report, investigation of strength evaluation methods for Spot-Welded joints), Trans. Jpn. Soc. Mech. Eng. 1993, 59(562): 131-137.

[11]EN12663. Railway applications-Structural requirements of railway vehicle bodies (part1). European Committee for Standardization (CEN) 2010. 